\title{
Utilization of HIV Counselling and Testing Services in Urban and Rural Communities in Eastern Region of Ghana: Implications for Achieving Universal HCT Coverage
}

\author{
Phyllis Dako-Gyeke (PhD.)
}

gyekenay@yahoo.com

\author{
Esther Boatemaa Agyapong (Msc.) \\ Department of Social and Behavioural Sciences, School of Public Health, \\ College of Health Sciences, University of Ghana, \\ Legon Holy Family Nursing Training College, Nkawkaw, Eastern Region, Ghana
}

Doi:10.5901/ajis.2014.v3n4p239

Abstract

Although HIV Counselling and Testing (HCT) is a cornerstone to HIV prevention and treatment, only a few Ghanaians are aware of their HIV sero-status. To ensure that HCT functions as a gateway to AIDS-related care, the Ministry of Health/Ghana Health Service is working to achieve universal HIV testing coverage in the country by 2015. The aim of this study was to determine awareness of HCT as well as factors influencing utilization of HCT in Kwawu West Municipality. This was a cross sectional study which employed quantitative approaches. Nkawkaw township which, is a high-risk area for HIV infection, was selected for the study where 400 questionnaires were administered to community members. Data was entered and analyzed using EPI-INFO version 3.4.1. Descriptive statistics were run to describe the distribution of the data. Also, chi square test was run to demonstrate associations between the dependent and independent variables. The results showed high (89\%) HCT awareness in the communities, yet only $29.2 \%$ of respondents have tested for HIV. Reasons for uptake included personal interest in knowing their HIV status (39.3\%), pregnancy (22.2\%), blood donation (11.1\%) and for marriage purposes (10.2\%). On the contrary, fear of knowing one's status was a major reason why many did not test. Considering gaps in HCT awareness and uptake of services we propose that educational programmes on HCT must be developed and implemented across these communities. Also, educational programmes must, in addition to awareness creation, encourage uptake of HCT services.

Keywords: HIV and AIDS, Counselling and Testing, HCT, Eastern Region, Ghana, Urban, Rural

\section{Introduction}

To ensure that HCT functions as a gateway to AIDS-related care, the Ministry of Health/Ghana Health Service is working to achieve universal HIV testing coverage by 2015. In the year 2011 it was estimated that, 34.0 million people were living with HIV globally (UNAIDS, 2012). Although the burden of the epidemic continues to vary considerably between countries and regions about $0.8 \%$ of adults aged $15-49$ years worldwide are living with the disease (UNAIDS, 2012). Current statistics indicate Sub-Saharan Africa remains most severely affected, with nearly 1 in every 20 adults (4.9\%) living with HIV and accounting for $69 \%$ of the people living with HIV worldwide (UNAIDS, 2012). Over the years HIV surveillance in Ghana indicates the disease is firmly established within the whole society, and sub-populations with higher prevalence and risk of transmission remain a reservoir for sustaining the epidemic (NACP/GAC, 2009).

Since HIV and AIDS has no cure, the approach for controlling this menace largely focuses on preventive strategies (NACP, 2008). Among these preventive measures are; counselling and testing, prevention of mother to child transmission, management of sexually transmitted infections, condom use promotion, safe blood transfusion, HIV exposure prevention in the health care setting, health promotion and demand creation (UNAIDS, 2000). Counselling and testing has been identified as an essential component of the comprehensive strategy of preventing new infections and or re-infection among the general populace and also the gateway to treatment, care, and prevention (NACP, 2008).

Studies show that counselling and testing is associated with the adoption of preventive health behaviour and it is also cost effective (Obermeyer et al., 2007). According to WHO/UNAIDS (2004) four types of testing are clearly distinguished and recommended. These include: counselling and testing (CT), routine offer of HIV testing by health care practitioners, diagnostic HIV testing and mandatory HIV testing. This indicates that there has been a shift from voluntary counselling and testing (VCT) to HIV counselling and testing (HCT). These four types of HIV testing have been put into 
two main categories namely; Client initiated testing and provider initiated testing. The situation where a client voluntarily walks into a CT site and requests to be tested is Client initiated testing (counselling and Testing-CT) which used to be called voluntary counselling and testing. The provider initiated testing include diagnostic HIV testing, mandatory testing and routine offer of HIV testing by health care providers. Diagnostic testing is initiated whenever a person shows signs and symptoms that are consistent with HIV related disease. It aids clinical diagnosis and management, which is usually requested by the clinician.

Unfortunately, the low level of knowledge of HIV status among people living with HIV presents an unwanted window for transmission within the general population (NACP, 2006). In order to get more people to know their status, the National AIDS Control Programme (NACP) established seven hundred and eighty-one counselling and testing centres across the country as at December 2009 (NACP, 2009). Also outreach counselling and testing has been embarked upon by all District Health Management Teams (DHMT) and the programme has a slogan 'know your status campaign' (NACP, 2008).

Despite expenses and efforts tailored towards HIV prevention and control, these resources have been under utilized throughout the country (NACP, 2008). Statistics indicate only $8 \%$ of the populace know about their HIV serostatus since its inception in 2006.

Unfortunately, the case of Kwawu West Municipal Area in the Eastern Region of Ghana is of no exception. Records obtained from the Kwawu West municipal health directorate indicate a low utilization of HCT services. In 2008, two thousand seven hundred and ten (2,710) clients were counselled and tested for HIV. However, in 2009, only 2,380 people, representing about $12 \%$ reduction from the previous year, utilized the HCT. This decline was recorded despite an outreach programme embarked upon within the community. Meanwhile at the national level there was $189 \%$ increment in the number of people who tested for HIV (NACP, 2008). This not withstanding, HIV prevalence among HCT clients in the municipality was $13.5 \%$ and $15.8 \%$ in 2008 and in 2009, respectively. This is two times higher than the national figure of $6.2 \%$ (NACP, 2008). To help gain a better understanding of declines in uptake of HCT services within this locality, this study was aimed at determining the level of awareness of HCT within the Kwawu West Municipality and also examine factors that influence the use of HCT services.

\section{Methodology}

This was a cross-sectional quantitative study carried out in Nkawkaw - a municipal capital of Kwawu West Municipality, Eastern Region, Ghana. The 2000 National Population and Housing Census put the municipal population at 162,400. The infrastructure of the health delivery system of the district consists of a Mission hospital, 3 private hospitals, and 6 Reproductive and Child health Centres all located at Nkawkaw.

Nkawkaw was selected and communities determined based on rural/urban characteristics and proximity to HCT centres. In all, four communities were selected: two (Mission and Nkawkaw Kuma) were rural located at the outskirts of the town and two urban (Adoagyiri and Akuajoo). Mission and Adoagyiri were selected because the two HCT centres are located in these two communities. The other two communities-Nkawkaw Kuma and Akuajoo were selected using simple random sampling. The names of all the communities which, were located at the outskirts of the town were written on pieces of paper and one community randomly picked. A 95\% confidence level and a proportion estimate formula was used to determine the sample size of 400. People living in Nkawkaw Township between the ages of 15-64 years were recruited. One adult in each household was selected by simple random sampling and then interviewed. Minors in school and in the communities were interviewed confidentially, after seeking ascent from parents.

Four hundred questionnaires, 100 in each community, were administered. EPI-INFO version 3.4.1 was used for the data entry, cleaning and analysis. Descriptive statistics (percentages and frequencies) were run. Tests for associations between dependent and independent variables were also done using chi-square. Ethical clearance for the study was obtained from the Ethical Review Committee of the Ghana Health Service.

\section{Results}

This study involved 400 respondents comprising of 189 (47.2\%) males and 211 (52.8\%) females (Refer to Table 1). Respondents within the 15-24 age group consisted of $37.2 \%$ of total respondents. Most of the respondents were JHS graduates (38.5\%) with $22.8 \%$ being SHS graduates. Most (85\%) of the respondents were Christians, with $12.5 \%$ and 1.5\% being Muslims and traditionalists, respectively. With regards to marital status, 221 (55.2\%) and 132 (33.0\%) of the respondents were singles and married, respectively. The remaining $11.7 \%$ were divorced, widowed, separated or 
cohabiting.

Table 1. Background Characteristics of Respondents

\begin{tabular}{|c|c|c|}
\hline \multicolumn{3}{|c|}{ Characteristics of Respondents $(\mathrm{N}=400)$} \\
\hline Sex & $\mathbf{n}$ & $\%$ \\
\hline Male & 189 & 47.2 \\
\hline Female & 211 & 52.8 \\
\hline \multicolumn{3}{|l|}{ Education } \\
\hline No Education & 40 & 10 \\
\hline Junior High School & 154 & 38.5 \\
\hline Senior High School & 114 & 28.5 \\
\hline Post Secondary/Technical & 22 & 5.5 \\
\hline Tertiary & 64 & 16.0 \\
\hline Others & 26 & 6.5 \\
\hline \multicolumn{3}{|l|}{ Age } \\
\hline $15-24$ & 149 & 37.2 \\
\hline $25-34$ & 132 & 33.0 \\
\hline $35-44$ & 61 & 15.2 \\
\hline 45 and Above & 58 & 14.4 \\
\hline \multicolumn{3}{|c|}{ Marital Status } \\
\hline Single & 221 & 55.2 \\
\hline Married & 132 & 33.0 \\
\hline Cohabiting & 14 & 3.5 \\
\hline Separated/Divorced & 19 & 4.7 \\
\hline Widowed & 14 & 3.5 \\
\hline \multicolumn{3}{|c|}{ Community Tenure of Respondents } \\
\hline Less than 1 year & 54 & 13.5 \\
\hline 1-5 years & 122 & 30.5 \\
\hline 6-10 years & 69 & 17.2 \\
\hline More than 10 years & 155 & 38.8 \\
\hline \multicolumn{3}{|c|}{ Religion } \\
\hline Christianity & 341 & 85.2 \\
\hline Islam & 50 & 12.5 \\
\hline Traditional & 6 & 1.5 \\
\hline Others & 3 & 0.8 \\
\hline \multicolumn{3}{|c|}{ Employment Status } \\
\hline Employed & 288 & 72 \\
\hline Unemployed & 112 & 28 \\
\hline Total & 400 & $100 \%$ \\
\hline
\end{tabular}

\section{Awareness of HCT and Knowledge of HCT Centers}

Awareness of HIV Counselling and Testing among respondents was very high (88.8\%). In the various communities, awareness was comparatively high among respondents from Akuajoo (93\%). The lowest (79\%) awareness was recorded among respondents from Mission (Refer to Table 2). Also awareness was highest (92.7\%) among respondents aged between 45-54years old and lowest (53\%) among those aged between 55-64years. However, knowledge of HCT centers was highest among respondents aged between 25-34years and lowest among the youngest age group (15-24yeras) (Refer to Table 2). Also those who had stayed in the community between 6-10years had the highest knowledge (88.4\%) about testing centres. 
Table 2: Awareness and Knowledge

\begin{tabular}{|c|c|}
\hline \multicolumn{2}{|c|}{ Awareness of HCT by Community and Age } \\
\hline Characteristic & Awareness (\%) \\
\hline \multicolumn{2}{|l|}{ Community } \\
\hline Adoagyiri & 92 \\
\hline Nkawkawkuma & 91 \\
\hline Mission & 79 \\
\hline Akuajoo & 93 \\
\hline \multicolumn{2}{|l|}{ Age in years } \\
\hline $15-24$ & 88 \\
\hline $25-34$ & 91.7 \\
\hline $35-44$ & 91.8 \\
\hline $45-54$ & 92.7 \\
\hline $55-64$ & 53 \\
\hline \multicolumn{2}{|c|}{ Knowledge of HCT Centers by Age and Community Tenure } \\
\hline Characteristic & Knowledge (\%) \\
\hline \multicolumn{2}{|l|}{ Age in years } \\
\hline $15-24$ & 76.5 \\
\hline $25-34$ & 87.9 \\
\hline $35-44$ & 82.0 \\
\hline $45-54$ & 80.5 \\
\hline $55-64$ & 58.8 \\
\hline Total & 80.8 \\
\hline \multicolumn{2}{|c|}{ Community tenure } \\
\hline Less than 1 year & 72.2 \\
\hline $1-5$ years & 78.7 \\
\hline $6-10$ years & 88.4 \\
\hline More than 10 years & 72.9 \\
\hline Total & 77.2 \\
\hline
\end{tabular}

\section{Uptake of HIV Counselling and Testing Services}

Notwithstanding the high awareness of HCT, as well as high knowledge of HCT centres, number of people that had undergone HIV counselling and testing in the area was found to be low. Only $117(29.3 \%)$ indicated they had taken an HIV test. The findings indicate that $57.2 \%$ of those who had tested were females. About a third (29\%) of them were from Nkawkawkuma. The lowest percentage (21.3\%) of those who had tested was from Mission. Also, high percentages of those who had tested for HIV where those with either Junior High School level (31.6\%) of education or tertiary education (27.4\%).

Table 3: Use of HIV Testing and Counselling Services

\begin{tabular}{|c|c|c|}
\hline \multicolumn{3}{|c|}{ HIV Testing Among Respondents ( $\mathrm{N}=117$ ) } \\
\hline Characteristic & $\mathrm{N}$ & $\%$ \\
\hline Sex & & \\
\hline Male & 50 & 42.7 \\
\hline Female & 67 & 57.2 \\
\hline Total & 117 & 100 \\
\hline \multicolumn{3}{|l|}{ Communities } \\
\hline Adoagyiri & 29 & 24.7 \\
\hline Nkawkawkuma & 34 & 29.0 \\
\hline Mission & 25 & 21.3 \\
\hline Akuajoo & 29 & 24.7 \\
\hline Total & 117 & 100 \\
\hline
\end{tabular}




\begin{tabular}{|c|c|c|}
\hline Education & & \\
\hline No Education & 6 & 5.1 \\
\hline JHS & 37 & 31.6 \\
\hline SHS & 29 & 24.8 \\
\hline Post Sec/Voc/Tech & 6 & 5.1 \\
\hline Tertiary & 32 & 27.4 \\
\hline Others & 7 & 6 \\
\hline Total & 117 & 100 \\
\hline
\end{tabular}

\section{Reasons for HCT Uptake}

The most important reason for HIV testing was found to be personal interest in knowing their HIV status which, recorded a percentage of $39.3 \%$.

The other key reasons for testing for HIV included pregnancy (22.2\%), blood donation (11.1\%) and for marriage purposes (10.2\%). Table 4 presents the ranking of the reasons for undergoing an HIV test.

Table 4: Reasons for undergoing HIV Counselling and testing

\begin{tabular}{|c|c|c|}
\hline Reason & $\mathrm{n}(\%)$ & Rank \\
\hline Interested in knowing personal HIV status & $46(39.3)$ & 1 \\
\hline Pregnancy & $26(22.2)$ & 2 \\
\hline Blood donation & $13(11.1)$ & 3 \\
\hline For marriage & $12(10.2)$ & 4 \\
\hline Employment Purposes & $7(5.9)$ & 5 \\
\hline Others & $7(5.9)$ & 6 \\
\hline Travelling Purposes & $4(3.4)$ & 7 \\
\hline Sickness of spouse & $2(1.7)$ & 8 \\
\hline$x^{2+2}$ & $117(100)$ & \\
\hline
\end{tabular}

\section{Reasons for not Testing}

In contrast, Table 5 shows that the major reason for which most people have not done an HIV test was fear (49.2\%). The expression of fear was in relation to testing positive and the possibility of being rejected by significant others such as family members and friends. Other respondents also did not test because they did not have money (13.6\%) or did not see its importance (23.1\%).

\begin{tabular}{|l|c|}
\hline \multicolumn{1}{|c|}{ Reason } & $\mathbf{n}(\%)$ \\
\hline Afraid of results & $130(49.2)$ \\
\hline Do not have money for test & $36(13.6)$ \\
\hline Do not see importance & $61(23.1)$ \\
\hline Others & $37(14.0)$ \\
\hline \multicolumn{1}{|c|}{ Total } & $\mathbf{2 6 4 ( 1 0 0 )}$ \\
\hline
\end{tabular}

\section{Discussion}

This study used quantitative methods to determine level of awareness of HIV Counselling and Testing in Nkawkaw and also examine factors that influence use of HCT services in this area. Although high percentage of respondents (88\%) are aware of HIV counselling and testing only $29 \%$ had been tested. This pattern is consistent with findings from the Ghana Demographic Health survey (2008). The GDHS found that although, about $70 \%$ of respondents know where to get an HIV test only $21 \%$ females and $14 \%$ of males aged between $15-49$ have ever been tested (GSS, 2009).

In addition, our findings reinforce sex disparities in HIV testing found in Ghana and also across several African countries (Yawson et, al, 2012; Snow et. al, 2010). Our study found $57 \%$ of females had tested compared with $42 \%$ of males. Similarly, a facility-based records study conducted by Yawson and colleagues (2012) in Ghana showed about $58 \%$ of females had tested for HIV across the country. This is also similar to findings from other African countries (Snow 
et al., 2010). The high HIV testing among females is usually explained by the encouraging efforts of the Prevention of Mother to Child Transmission (PMCT). In Ghana, pregnant women are offered HIV opt-out counselling and testing services as part of their antenatal care package. This routine HIV counselling and testing services might be the reason for more females accessing CT than males since Manavi and colleagues (2005) have also observed that outside prenatal programme women less frequently access HCT than the men.

Additionally, this study found other demographic factors were associated with HCT. This finding contradicts a study in Ethiopia which, revealed that biographic characteristics of respondents did not have significant association to the behaviour or practice of HCT (Alemayehu, 2010). In this study, education was found to be associated with undergoing HCT. It was observed that several respondents who have undergone HIV counselling and testing were people who have received tertiary education. This finding confirms a similar study conducted by Peltzer (2009) which, suggests that those with more formal education are likely to know their HIV status. On the contrary, a study in Uganda by Mpairwe and colleagues (2004) demonstrated that low educational background is associated with higher uptake of HCT.

Furthermore, with regard to awareness of HCT and age, this study found awareness among respondents aged between 25-54 years was higher as compared to the people who were 55 and above. This finding seems to have some commonalities with studies in Uganda and South Africa which indicate that being in the age group 25-35 is associated with the knowledge of CT services (Bwambale et al., 2008; Peltzer, 2009). It is worth noting however that, knowledge about HCT services was also high between the age group 36-54. High knowledge about awareness of HCT services could be attributed to the ongoing "know your status" campaign across the country (NACP, 2008). However, it will be key for the policy makers to ensure that awareness translates into utilization of the service within the communities.

The community in which a person resides also plays a significant role in the awareness and utilization of services. In this study awareness of HCT services was significantly higher in urban communities than in the rural communities. This confirms Peltzer's (2009) finding in South Africa that awareness about CT services in rural areas was low as compared to the urban areas. However, when it comes to HCT utilization more people have done the test in the rural communities than in the urban communities and this contradicts Peltzer's (2009) observation that those living in urban areas were more likely to have done HCT. The result indicates that, awareness about HCT services does not necessarily translate into utilization of such services. In addition, the study revealed that in the communities where there are no HCT facilities, more people have done the test than in the communities where the HCT centres are situated. The reason for the low testing in communities where the HCT centres are located may be due to the fact that they are familiar with the health workers and do not want their status to be known by them. This finding seems to support a study conducted in rural Malawi which concluded that, repeated HCT service rendered by healthcare workers outside the local area was universally accepted (Obare et al., 2009). This seems to imply that more people may accept HCT when testing is done by health workers who live outside their communities. People often avoid health centres that provide HIV services in their locality, as a result of fear of being seen by neighbours or community members (USAID, 2007; Human Rights Watch, 2008).

The major reason for which most people have not undergone an HIV test was fear. This expression of fear was in relation to testing positive and the possibility of being rejected by significant others such as family members and friends. Similarly, studies from elsewhere have observed that fear of testing positive, fear of social rejection, stigmatization and lack of confidentiality are among the most important factors which, negatively affect the utilization of HIV counselling and testing (Wanyenze et al., 2008; Wiktor et al., 1999; Antelman et al., 2001). Even though CT services all over the country are free (NACP, 2008), in this study $9 \%$ of the respondents indicated that they do not have money that is why they have not done the test. This response may be due to the perception that the test is done for a fee, implying that the community members are not aware that such services are for free in Ghana now. This finding also indicates gaps in the HCT educational programmes in the country.

\section{Conclusion}

HIV counselling and testing has been identified as the gateway for dealing with the challenges posed by the disease. Knowledge of one's sero-status is beneficial. For those who test negative, knowledge of status may lead toward the adoption of a more responsible healthy behaviour to remain negative. On the other hand, for those who test positive, they can also take more appropriate steps to get treatment and care which will improve their quality of life and their general well being. The study focused on exploring factors influencing the utilization of CT in Nkawkaw and its surrounding communities using a cross sectional and quantitative methods.

This study revealed that several factors interplay in a complex manner to influence the utilization of HCT. These 
factors include age, gender, educational level, and fear of testing positive. Also, the study concludes that awareness of HCT does not necessarily translate into testing for HIV.

Considering the influence of age, gender, and educational background on HCT utilization, educational programmes on HIV counselling and testing should be audience specific. The educational programmes should be packaged to meet the specific needs of different target populations. There is the need to promote HIV counselling and testing education at all levels including: personal, household, and institutional levels in the community. Every possible platform should be used to encourage uptake of HCT.

\section{References}

Alemayehu, B. (2010). Knowledge, Attitude, and Practice of Voluntary Counselling and Testing for HIV among University Students. Tigray, Northern Ethiopia. MEJS, 2 (1), 108-118.

Antelman, G., Smith-Fawzi, M.C., Kaaya, S., Mbwambo, J., Msamanga, G.I., Hunter, D.J. \& Fawzi, W.W. (2001). Predictors of HIV-1 Serostatus Disclosure: a Prospective Study Among HIV-Infected Pregnant Women in Dares Salaam, Tanzania. AIDS Care, 15, 1865-1874.

Bwambale, F.M., Ssali, S.N., Byaruhanga, S., Kalyango, J.N. \& Karamagi, C.A. (2008). Voluntary HIV counselling and testing among men in rural Western Uganda: implications for HIV prevention , BMC Public Health, 30 (8), 263.

Ghana Statistical Service (GSS), Noguichi Memorial Institute for Medical Research (NMIMR),\& ORC Macro (2004). Ghana Demographic and Health Survey, 2003. Calverton: MD.

Human Right Watch (2008). A question of life or death. Kenya AIDS Indicator Survey, 2007.

Manavi K, Welsby P.D. (2005). HIV Testing. BMJ, 330, 492-493.

Mpairwe, H., Muhangi, L.B., Namujju, P., Kisitu, A., Tumusiime, A., Muwanga, M., Whitworth, J., Onyango, S., Biryahwaho, B. \& Elliott, A. (2005). HIV Risk Perception and Prevalence in a Programme for Prevention of Mother-to-Child HIV Transmission: Comparison of Women Who Accept Voluntary Counselling and Testing and Those Tested Anonymously. Journal of Acquired Immune Deficiency Syndromes, 39 (3), 354-358.

NACP Bulletin (2006). HIVIAIDS in Ghana Current Projections Impact and Interventions. Quarterly Technical Bulletin, Ghana Health Service, 2(2), 3-5

NACP Bulletin (2008). HIV and AIDS Prevention, Treatment Care and Support Services in Ghana. NACP Bulletin, 5 (4), 6-7.

National AIDS/STI Control Programme (2008). Annual Report: Ghana Health Service.

National AIDS/STI Control Programme (2009). Annual Report: Ghana Health Service.

Obare, F., Fleming, P., Anglewicz, P., Thornton, R., Martinson F., Kapatuka, A., Poulin M., Watkins, S. \& Kohler, H.P. (2009). Acceptance of Repeat Population-Based Voluntary Counselling and Testing for HIV in Rural Malawi. Sexually Transmitted Infection, 85, 139-144.

Obermeyer, C. M. \& Osborn, M. (2007). The Utilization of Testing and Counselling for HIV: A Review of the Social and Behavioural Evidence. American Journal of Public Health, 97 (10), 1762-1774.

Peltzer, K., Matseke, G., Thembile, M., \& Mmapaseka, M., (2009). Determinants of knowledge of HIV status in South Africa: results from a population-based HIV survey. BMC Public Health, 9 (174).

Snow, R. C. , Madalane, M. \& Poulsen, M. (2010). Are men testing? Sex differentials in HIV testing in Mpumalanga Province, South Africa, AIDS Care, 22(9), 1060- 1065.

UNAIDS (2000). Costing Guidelines for HIV Prevention Strategies: Best Practice Collection. Geneva, Switzerland.

UNAIDS/WHO (2004). Policy Statement on HIV Testing: Joint United Nations Programme on HIV/AIDS. Geneva.

UNAIDS (2012). UNAID Report on the global AIDS epidemic. Retrieved from www.unads.org/unaids./2012/yr 2012_11:20_UNAIDS_Glo

USAID (2007). Measuring the degree of S\&D in Kenya: An index for HIV/AIDS facilities and providers. Taylor \& Francis Group.

Wanyenze, R., Madra, P. \& Ronald, A., (2008). Global HIV/AIDS Medicine (1st ed.). Elsevier Inc.

Wiktor, S.Z., Ekpini, E., Karon, J.M., Nkengasong, J., Maurice, C., Severin, S.T., Roeis, T.H., Kouassi, M.K., Lackritz, E.M., Coulibaly, I.M. \& Greenberg, A.E. (1999). Short course of Oral Zidovudine for Prevention of Mother-to-child Transmission of HIV-1 in Abidjan, Côte d'Ivoire: A Randomized trial. Lancet, 353, 781-785.

Yawson, A. E., Dako-Gyeke, P., and Snow R. (2012). Sex difference in HIV testing in Ghana, and Policy implications. AIDS Care, 24(9). 
